\title{
Effect of pretreatment with gabapentin on withdrawal movement associated with intravenous rocuronium injection
}

\author{
Jin Sun Yoon, Hee Jung Jeon, Sam Soon Cho, Jae Do Lee, Kyung Oh Kang, Sang Wook Ryu, and \\ Hong Seok Ko
}

Department of Anesthesiology and Pain Medicine, Seoul Veterans Hospital, Seoul, Korea

Background: The major disadvantage of rocuronium is the withdrawal movement associated with its injection. The analgesic effect of perioperative gabapentin has been evaluated. We investigated the effects of gabapentin on the withdrawal movement induced by rocuronium injection.

Methods: 86 ASA physical status I or II patients, aged 18-69 years who were scheduled to undergo elective surgery with general anesthesia were enrolled. Patients were randomly allocated into two groups to receive either gabapentin $600 \mathrm{mg}$ or placebo 2 hours prior to surgery. The patient's response to rocuronium injection was graded using a 4-point scale.

Results: The incidence of withdrawal movement after rocuronium administration was significantly lower in the gabapentin group ( $55.0 \%$ in the control group vs $28.6 \%$ in the gabapentin group). The number of patients with generalized response indicating severe pain, was 9 (22.5\%) in the control group and 3 (7.1\%) in the gabapentin group. Conclusions: Pretreatment with a single oral dose of gabapentin $600 \mathrm{mg}$ reduced the incidence and severity of withdrawal movement after rocuronium administration. (Korean J Anesthesiol 2011; 61: 367-371)

Key Words: Gabapentin, Injection, Pain, Rocuronium, Withdrawal movement.

Received: March 28, 2011. Revised: April 28, 2011. Accepted: May 3, 2011.

Corresponding author: Jin Sun Yoon, M.D., Department of Anesthesiology and Pain Medicine, Seoul Veterans Hospital, 6-2, Dunchon-dong, Gangdong-gu, Seoul 134-817, Korea. Tel: 82-2-2225-1415, Fax: 82-2-2225-1416, E-mail: medisun74@naver.com

(c) This is an open-access article distributed under the terms of the Creative Commons Attribution Non-Commercial License (http:// creativecommons.org/licenses/by-nc/3.0/), which permits unrestricted non-commercial use, distribution, and reproduction in any medium, provided the original work is properly cited. 


\section{Introduction}

Rocuronium is a commonly used steroidal non-depolarizing neuromuscular blocking agent with a rapid onset of action and an intermediate duration [1]. However, even in unconscious patients during anesthetic induction, rocuronium causes withdrawal movement of the injected hand or arm, or generalized movements of the body after intravenous injection. The major disadvantage of rocuronium is the pain associated with its injection, and generalized movements of the body caused by injection pain may even lead to reflux of gastric contents and pulmonary aspiration [2]. A number of treatment modalities have been recommended in an attempt to reduce withdrawal responses, such as priming technique, local warming at the injection site, pretreatment or mixing with ondansetron, lidocaine, tramadol, fentanyl, magnesium sulphate, sodium bicarbonate, alfentanil and antihistamine [3-8].

Gabapentin is a structural analogue of $\gamma$-amino butyric acid (GABA) and was initially introduced as an antiepileptic drug. The drug has also demonstrated antinociceptive, analgesic, and antihyperalgesic properties. Recently it has been used to treat acute and chronic pain after surgery, and to reduce postoperative opioid requirement [9-13].

To our knowledge, a limited number of studies have evaluated the potential influence of gabapentin in general anesthetic induction with rocuronium. This double-blind, randomized, placebo-controlled study aimed to investigate the effects of gabapentin on the incidence and severity of rocuronium injection pain and the changes in hemodynamic variables during anesthetic induction.

\section{Materials and Methods}

After obtaining approval from the institutional ethics committee and patients' written informed consent, 86 ASA physical status I or II patients, aged 18-69 years who were scheduled to undergo elective surgery with general anesthesia were enrolled. Exclusion criteria were as follows: patients with ASA physical status III or greater, neurological deficits, pregnancy, anticipated difficult airway, body weight more than $20 \%$ of ideal body weight, substance abuse, alcoholism, and those receiving analgesics, sedatives, hypnotics, antidepressants, hemodynamic instabilities during induction. Four patients were dropped from the study. Patients were randomly allocated into 2 groups (43 in each group) with the help of a computer generated table of random numbers to receive either gabapentin $600 \mathrm{mg}$ (Group G) or placebo (Group C) 2 hours prior to surgery.

None of the patients were premedicated, and standard monitoring with electrocardiogram, non-invasive blood pressure, and pulse oximetry was performed. Blood pressure was measured at 1-min intervals. An 18-G intravenous cannula was placed preoperatively in the vein on the dorsum of the hand in the ward and infusion of lactated Ringer's solution was started. Side effects of gabapentin including sedation, nausea, vomiting, somnolence, lightheadedness, dizziness, headache and visual disturbances were recorded before induction. If necessary, symptoms were treated. After $3 \mathrm{~min}$ of preoxygenation, $2.5 \%$ thiopental sodium $5 \mathrm{mg} / \mathrm{kg}$ was injected. When the verbal response and the eyelash reflex were abolished, an intubating dose of rocuronium $0.6 \mathrm{mg} / \mathrm{kg}$ was injected over 5 seconds and intravenous fluid was continously administered for 10 seconds. While rocuronium was being injected, withdrawal movement was graded as follows: grade $0=$ no response, grade $1=$ movement $/$ withdrawal at the wrist only, grade 2 = movement/withdrawal involving the arm only (elbow/shoulder), and grade 3 = generalized response with movement/withdrawal in more than one extremity, cough, or breath-holding [14]. Mean blood pressure (MBP) and heart rate (HR) were recorded before the induction, 1 min before intubation, $1 \mathrm{~min}$ and $5 \mathrm{~min}$ after intubation.

With reference to the previous study $[15,16]$, the incidence of withdrawal movements was predicted to be approximately $60 \%$, and a $50 \%$ reduction in incidence to $30 \%$ was considered to be clinically relevant. Power analysis showed that 82 patients were needed for $80 \%$ power $(\beta=0.2)$ and $95 \%$ significance level $(\alpha=0.05)$ to detect $50 \%$ reduction in incidence. 43 patients were enrolled per group assuming a $5 \%$ dropout rate. Statistical analyses were performed using SPSS 14.0 for Windows (Statistical Package for Social Science, SPSS Inc, Chicago, IL, USA). Data are expressed as mean \pm standard deviation (SD) or numbers (percentages). Discrete variables such as gender, ASA, the incidence of withdrawal movement were analyzed using Chi-square or Fisher's exact test. Student's t-test or MannWhitney test were used to compare continuous variables such as age, weight, height, mean blood pressure (MBP) and heart rate (HR) between groups. ANOVA for repeated measures was used to compare the changes in mean hemodynamic variables within the group. A P value of less than 0.05 was considered statistically significant.

\section{Results}

Both groups were comparable with respect to age, gender, ASA status, weight, and height (Table 1). None of the patients in Group $\mathrm{G}$ showed gabapentin-related side effects such as sedation, nausea, vomiting, somnolence, lightheadedness, dizziness, headache and visual disturbances before anesthetic induction. The overall incidence (Grade 1-3) of withdrawal movement after rocuronium administration was significantly different between both the groups ( $55.0 \%$ in the Group C vs 
Table 1. Patient Demographic Characteristics

\begin{tabular}{lcc}
\hline & Group C $(\mathrm{n}=40)$ & Group G $(\mathrm{n}=42)$ \\
\hline Age (yr) & $58.9 \pm 8.3$ & $60.0 \pm 5.2$ \\
Gender (M/F) & $26 / 14$ & $28 / 14$ \\
ASA (I/II) & $10 / 30$ & $11 / 31$ \\
Weight (kg) & $64.9 \pm 9.9$ & $63.8 \pm 8.2$ \\
Height (cm) & $163.2 \pm 9.2$ & $162.5 \pm 9.2$
\end{tabular}

Values are mean \pm SD or numbers. Group C: control group, Group G: gabapentin group.
Table 2. Incidence and Severity of Withdrawal Movement

\begin{tabular}{ccc}
\hline & Group C $(\mathrm{n}=40)$ & Group G $(\mathrm{n}=42)$ \\
\hline Grade 0 & $18(45.0 \%)$ & $30(71.4 \%)^{*}$ \\
Grade 1 & $3(7.5 \%)$ & $0(0 \%)$ \\
Grade 2 & $10(25.0 \%)$ & $9(21.4 \%)$ \\
Grade 3 & $9(22.5 \%)$ & $3(7.1 \%)^{*}$ \\
\hline
\end{tabular}

Values are presented as number of patients. Group C: control group, Group G: gabapentin group. Grade 0: no movement, Grade 1: movementat the wrist only, Grade 2: movement involving upper arm and shoulder, Grade 3: generalized movement. ${ }^{*} \mathrm{P}<0.05$ compared with group C.

Table 3. Hemodynamic Changes

\begin{tabular}{|c|c|c|c|c|}
\hline & \multicolumn{2}{|c|}{ Group C $(n=40)$} & \multicolumn{2}{|c|}{ Group G $(n=42)$} \\
\hline & HR (BPM) & MBP (mmHg) & HR (BPM) & MBP (mmHg) \\
\hline Baseline & $74.1 \pm 10.9^{\S}$ & $93.8 \pm 11.4^{\S}$ & $73.5 \pm 12.8^{\S}$ & $92.7 \pm 10.7^{\neq, \S}$ \\
\hline Pre-1m & $82.7 \pm 11.8^{\S}$ & $89.8 \pm 11.8^{\S}$ & $75.4 \pm 13.1^{*, \S}$ & $81.2 \pm 12.2^{*,+, \S, \|}$ \\
\hline Post-1m & $97.8 \pm 13.6^{\dagger, \uparrow, \|}$ & $109.2 \pm 17.1^{\dagger, \ddagger, \|}$ & $95.1 \pm 18.8^{\dagger, \neq, \|}$ & $113.7 \pm 15.9^{\dagger, \neq, \|}$ \\
\hline Post-5m & $81.4 \pm 14.6^{\S}$ & $88.9 \pm 10.6^{\S}$ & $79.4 \pm 14.2^{\S}$ & $91.5 \pm 10.2^{\neq, \S}$ \\
\hline
\end{tabular}

Values are mean \pm SD. Group C: control group, Group G: gabapentin group. Baseline: before induction, Pre-1m: 1 min before intubation, Post$1 \mathrm{~m}$ : 1 min after intubation, Post-5m: 5 min after intubation, $* \mathrm{P}<0.05$ compared with group $\mathrm{C},{ }^{\dagger} \mathrm{P}<0.05$ compared with baseline value within the group, ${ }^{\ddagger} \mathrm{P}<0.05$ compared with Pre- $1 \mathrm{~m}$ within the group, ${ }^{\S} \mathrm{P}<0.05$ compared with Post-3m within the group, " $\mathrm{P}<0.05$ compared with Post- $5 \mathrm{~m}$ within the group.

28.6\% in the Group G, P = 0.02). The number of patients with grade 3 withdrawal response, indicating severe pain, was 9 (22.5\%) and 3 (7.1\%) in Group C, and Group G, respectively $(\mathrm{P}<$ 0.05, Table 2).

Baseline hemodynamic variables were similar between the two groups (Table 3). HR and MBP at 1 min before intubation were significantly lower in Group G compared with Group C. However, HR and MBP at 1 and 5 min after intubation were comparable between the two groups. Comparison of HR and MBP within each group showed significant differences among values with the course of time.

\section{Discussion}

The present study demonstrated that pretreatment with a single dose of gabapentin $600 \mathrm{mg} 2$ hours before surgery significantly reduced the incidence and the severity of withdrawal movement induced by rocuronium administration. Moreover, HR and MBP at 1-min before tracheal intubation were lower in patients pretreated with gabapentin.

The incidence of withdrawal movement associated with rocuronium injection has been reported in $50-100 \%$ of patients [15-18]. In our study, the incidence of withdrawal response was $55.0 \%$ in the control group. Compared with the previous study, the occurrence of withdrawal movement was comparatively lower in our study. Age and gender play important roles in rocuronium-induced withdrawal movements [19-22]. The overall incidence of rocuronium-induced pain was lower in older patients aged over 65 years compared with that in the young patients aged between $20-40$ years in the placebo group [19]. Gender difference in severity and incidence of rocuronium-induced pain also exists in adults [21]. A previous study has suggested that females reported more frequent and severe pain responses than males. Females are considered to be $20-25 \%$ more sensitive to rocuronium than males [22]. In our study, mean age of patients in the control group was $58.9 \pm 8.3$ years and the ratio of females to males was $35 \%$. The relatively low incidence of rocuronium-induced pain may be related with patients' characteristics such as older age and male dominance.

Gabapentin is an antiepileptic drug and a structural analogue of $\gamma$-amino butyric acid (GABA). It has been proved to be effective in controlling acute postoperative pain and reducing postoperative opioid requirement [9-13]. In addition, pretreatment with gabapentin attenuated the pressor response to laryngoscopy and tracheal intubation [23]. Gabapentin is not metabolized in humans and its elimination is dependent on renal clearance. The elimination half-life of gabapentin is 5 to 7 hours after an oral dose of 200 to $400 \mathrm{mg}$. After a single dose of $300 \mathrm{mg}$, maximum plasma concentration is reached in about $2-3$ hours. The bioavailability of a $600 \mathrm{mg}$ single oral dose of gabapentin is about $40 \%$ and decreases with an increasing dose. Single dose of $600 \mathrm{mg}$ administered 2 hours before surgery 
is within the recommended dose limits of 300 to $1200 \mathrm{mg}, 3$ times a day [24]. It seems to be clinically impractical to use oral gabapentin with a delayed onset of action and a long half-life, for preventing temporary withdrawal movement. However, since patients who were treated with gabapentin before surgery benefited from its influence on maintaining the hemodynamic stability after tracheal intubation and postoperative analgesic effect, pretreatment with oral gabapentin deserves consideration.

Gabapentin is also regarded as a safe drug. It has fewer side-effects and minor interactions with other drugs. Older patients occasionally show increased sensitivity to drugs and doses of gabapentin may be adjusted to their age. We did not observe any adverse effects associated with a dose of $600 \mathrm{mg}$ of gabapentin and it was well tolerated.

Although the exact mechanism of action of gabapentin is unknown, proposed mechanisms are as follows: its ability to increase the concentration and the rate of GABA synthesis in the brain; bind with high affinity to binding sites in brain tissues that are associated with auxiliary subunit of voltagesensitive calcium channel ( $\alpha_{2} \delta$ subunits); reduce the release of monoamine neurotransmitters; inhibit voltage-activated sodium channels; and increase serotonin concentration in human blood $[25,26]$. The drug inhibits voltage-gated calcium channels in the membrane and acts in a similar way to calcium channel blockers [27]. Calcium channel blockers have shown antinociceptive effects in animals [28]. Miranda et al. suggested that a substance with a calcium channel blocking effect should probably have some antinociceptive properties. We speculated that the calcium channel blocking property of gabapentin might also have alleviated HR and MBP before tracheal intubation in the gabapentin group.

In conclusion, pretreatment with a single oral dose of $600 \mathrm{mg}$ gabapentin attenuated the incidence and severity of withdrawal movement after rocuronium administration. The dose used in this trial well tolerated and the patients did not manifest any side effects. Further studies may be needed to investigate the appropriate dose of gabapentin and compare gabapentin with other treatment modalities for preventing withdrawal movement related to rocuronium injection.

\section{References}

1. Wright PM, Caldwell JE, Miller RD. Onset and duration of rocuronium and succinylcholine at the adductor pollicis and laryngeal adductor muscles in anesthetized humans. Anesthesiology 1994; 81: 1110-5.

2. Lui JT, Huang SJ, Yang CY, Hsu JC, Lui PW. Rocuronium induced generalized spontaneous movements cause pulmonary aspiration. Chang Gung Med J 2002; 25: 617-20.

3. Lee JI, Lim SH, Lee SE, Kim YH, Lee JH, Lee KM, et al. Priming technique can alleviate the withdrawal responses associated with intravenous administration of rocuronium. Korean J Anesthesiol 2009; 56: 628-33.

4. Mahajan C, Rath GP, Bithal PK, Prabhakar H, Yadav R, Dube SK. Local warming at injection site helps alleviate pain after rocuronium administration. J Anesth 2010; 24: 845-8.

5. Memiş D, Turan A, Karamanlioğlu B, Süt N, Pamukçu Z. The prevention of pain from injection of rocuronium by ondansetron, lidocaine, tramadol, and fentanyl. Anesth Analg 2002; 94: 1517-20.

6. Singh M, Chauhan H, Rath GP, Prabhakar H, Bithal PK, Dash HH. Effect of narcotic pretreatment on pain after rocuronium injection: a randomized, double-blind controlled comparison with lidocaine. J Anesth 2007; 21: 510-2.

7. Turan A, Memis D, Karamanlioglu B, Sut N, Pamukcu Z. The prevention of pain from injection of rocuronium by magnesium sulphate, lignocaine, sodium bicarbonate and alfentanil. Anaesth Intensive Care 2003; 31: 277-81.

8. Lee HJ, Han SJ, Kim H, Lee IO, Kong MH, Kim NS, et al. Antihistamine pretreatment to reduce incidence of withdrawal movement after rocuronium injection. J Korean Med Sci 2009; 24: 879-82.

9. Fassoulaki A, Patris K, Sarantopoulos C, Hogan Q. The analgesic effect of gabapentin and mexiletin after breast surgery for cancer. Anesth Analg 2002; 95: 985-91.

10. Fassoulaki A, Triga A, Melemeni A, Sarantopoulos C. Multimodal analgesia with gabapentin and local anesthetics prevents acute and chronic pain after breast surgery for cancer. Anesth Analg 2005; 101: 1427-32.

11. Fassoulaki A, Stamatakis E, Petropoulos G, Siafaka I, Hassiakos D, Sarantopoulos C. Gabapentin attenuates late but not acute pain after abdominal hysterectomy. Eur J Anaesthesiol 2006; 23: 136-41.

12. Pandey CK, Priye S, Singh S, Singh U, Singh RB, Singh PK. Preemptive use of gabapentin significantly decreases postoperative pain and rescue analgesic requirements in laparoscopic cholecystectomy. Can J Anaesth 2004; 51: 358-63.

13. Turan A, Karamanlioğlu B, Memiș D, Usar P, Pamukçu Z, Türe M. The analgesic effects of gabapentin after total abdominal hysterectomy. Anesth Analg 2004; 98: 1370-3.

14. Shevchenko Y, Jocson JC, McRae VA, Stayer SA, Schwartz RE, Rehman M, et al. The use of lidocaine for preventing the withdrawal associated with the injection of rocuronium in children and adolescents. Anesth Analg 1999; 88: 746-8.

15. Borgeat A, Kwiatkowski D. Spontaneous movements associated with rocuronium: is pain on injection the cause? Br J Anaesth 1997; 79: 382-3.

16. Steegers MA, Robertson EN. Pain on injection of rocuronium bromide. Anesth Analg 1996; 83: 203.

17. Reedy MS, Chen FG, Ng HP. Effect of ondansetron pretreatment on pain after rocuronium and propofol injection: a randomized, double-blind controlled comparison with lidocaine. Anaesthesia 2001; 56: 902-5.

18. Chiarella AB, Jolly DT, Huston CM, Clanachan AS. Comparison of four strategies to reduce the pain associated with intravenous administration of rocuronium. Br J Anaesth 2003; 90: 377-9.

19. Park SJ, Park HJ, Choi JY, Kang HS, Choi HS. The influence of age and gender on remifentanil EC(50) for preventing rocuronium induced withdrawal movements. Korean J Anesthesiol 2010; 58: 244-8. 
20. Mencke T, Schreiber JU, Knoll H, Stracke C, Kleinschmidt S, Rensing $\mathrm{H}$, et al. Women report more pain on injection of a precurarization dose of rocuronium: a randomized, prospective, placebo-controlled trial. Acta Anaesthesiol Scand 2004; 48: 1245-8.

21. Mencke T, Beerhalter U, Fuchs-Buder T. Spontaneous movements, local reactions and pain on injection of rocuronium. A comparison between female and male patients. Acta Anaesthesiol Scand 2001; 45: 1002-5.

22. Mencke T, Soltesz S, Grundmann U, Bauer M, Schlaich N, Larsen $\mathrm{R}$, et al. Time course of neuromuscular blockade after rocuronium. Anaesthesist 2000; 49: 609-12.

23. Fassoulaki A, Melemeni A, Paraskeva A, Petropoulos G. Gabapentin attenuates the pressor response to direct laryngoscopy and tracheal intubation. Br J Anaesth 2006; 96: 769-73.

24. Rowbotham M, Harden N, Stacey B, Bernstein P, Magnus-Miller L. Gabapentin for the treatment of postherpetic neuralgia: a rando- mized controlled trial. JAMA 1998; 280: 1837-42.

25. Taylor CP, Gee NS, Su TZ, Kocsis JD, Welty DF, Brown JP, et al. A summary of mechanistic hypotheses of gabapentin pharmacology. Epilepsy Res 1998; 29: 233-49.

26. Gee NS, Brown JP, Dissanayake VU, Offord J, Thurlow R, Woodruff GN. The novel anticonvulsant drug, gabapentin (neurontin), binds to the $\alpha_{2} \delta$ subunits of a calcium channel. J Biol Chem 1996; 271 : 5768-76.

27. Sarantopoulos C, McCallum B, Kwok WM, Hogan Q. Gabapentin decreases membrane calcium currents in injured as well as in control mammalian primary afferent neurons. Reg Anesth Pain Med 2002; 27: 47-57.

28. Miranda HF, Bustamante D, Kramer V, Pelissier T, Saavedra H, Paeile C, et al. Antinociceptive effects of $\mathrm{Ca}^{2+}$ channel blockers. Eur J Pharmacol 1992; 217: 137-41. 